\title{
Entrevista com Susana de Araújo Gastal. “TURISMO E CULTURA CRIAM INTERTEXTUALIDADES”
}

\author{
Roque Pinto \& Zara Pinto-Coelho
}

\section{Interview with Susana de Araújo Gastal. “Tourism AND CULTURE CREATE INTERTEXTUALITIES"}

No quadro da edição deste volume intitulado "Discursos e Imagens do Turismo Cultural", quisemos auscultar a opinião de investigadores das Ciências Sociais, sobre o estado da arte na área, no Brasil e em Portugal. Elaborámos um conjunto de questões e convidámos vários colegas a responder por escrito às mesmas. Susana de Araújo Gastal, professora titular e pesquisadora do Programa de Pós-Graduação em Turismo e Hospitalidade da Universidade de Caxias do Sul (Brasil), autora de diversos livros e artigos relativos à temática de cultura e turismo, foi uma das investigadoras que gentilmente acedeu ao nosso convite. Agradecemos o seu trabalho e cuidado.

1. As possibilidades, tensões e conflitos que atravessam o turismo cultural, enquanto fenómeno simultaneamente local e global, podem ser vistos como oportunidades para ampliar os territórios de investigação neste domínio. Neste contexto, o que podem as Ciências Sociais e Humanas fazer para transformar este objeto tradicionalmente "mal-dito" (isto é, pouco relevante e até pouco "nobre") num objeto "bem-dito"?

Trabalho dentro de um contexto teórico e metodológico associado à Semiótica, especialmente considerando a teoria do texto e a desconstrução. A partir da década de 1970, aportes semiotizados aparecem, implícita ou explícita, na teorização de áreas tão diversas como a Arquitetura, a História, a Geografia ou a Psicanálise e, de certa forma, no Turismo, com Urry e Urbain, para ficar apenas nestes dois. Tais aproximações passaram a ser tratadas como pós-modernidade, que por sua vez é apresentada como a expressão cultural do sistema econômico globalizado.

David Harvey, por exemplo, escreveu que "o pós-moderno consiste em ver a obra como um 'texto', com sua 'retórica' e seu 'idioleto'” (1992, p. 49) e que a "vida cultural é, pois, vista como uma série de textos em interseção com outros textos, produzindo mais textos" (1992, p. 59). Esse entrelaçamento intertextual teria vida própria. Se aplicarmos tais teorizações ao turismo cultural, precisaremos considerar, primeiro, que nestas reflexões contemporâneas desaparecem os antagonismos entre cultura erudita e cultura popular. Tratamos como cultura, e ponto final. Outra alteração importante, o conceito 
"cultura" deixa de abranger apenas expressões que eram tidas como "maiores", por exemplo, artes plásticas e arquitetura, para debruçar-se sobre manifestações cotidianas como a comida de rua, a música no metro, o grafite. Urry inclui, inclusive, os esportes como expressão cultural. Ato continuo, o turismo cultural seguirá as mesmas trilhas, o pós-turista buscando interagir com os cotidianos dos lugares que visita.

As Ciências Sociais ainda alimentam, em muitos casos, o antagonismo erudito (acadêmico) versus popular, neste último associando saberes como os relacionados ao turismo. Hoje vivemos em um mundo em mobilidades e a área do Turismo estuda pessoas e situações culturais pautadas pela mobilidade. Congressos da área começam a sinalizar a quebra dos preconceitos acadêmicos, frente aos novos cenários.

2. Podemos dizer que o discurso de turismo produzido pelas Ciências Sociais e Humanas, em especial desde os anos 9o, implicou um deslocamento da ideia de impacto para as ideias de mudança, transformação, adaptação e apropriação. Quais são os riscos e as oportunidades que estas novas dinâmicas colocam para quem estuda as relações entre turismo e cultura, num quadro de colonização das políticas científicas pelos imperativos da relevância e da intervenção e de eleição do turismo como setor estratégico de desenvolvimento nacional e internacional?

Como colocado anteriormente, novas concepções teóricas alteraram o entendimento da cultura. $\mathrm{Na}$ atualidade, as expressões cotidianas também são vistas como "culturais", um reconhecimento que era atributo exclusivo do patrimônio extraordinário. Da mesma forma, o turismo cultural passa a incluir itens como gastronomia e momentos de socialização cotidiana das localidades, levando a que destinos urbanos disputem visitantes que antes eram orientados para espaços junto à natureza.

Dizer cultura, hoje, é reconhece-la como importante segmento econômico, como o faz a Unesco quando apresenta propostas como a economia criativa ou as cidades criativas. Isso não significa rebaixar a cultura e transformá-la em "produto", mas justamente o contrário. Assim colocado, significa reconhecer os fazeres culturais como autorais e como um trabalho a ser remunerado. Turismo e cultura criam intertextualidades e interligam-se em uma mesma cadeia produtiva, cada vez mais presente. Nossas pesquisas precisam ter, também, este indicativo intertextual.

O problema com o qual nos defrontamos em termos de impactos, talvez seja outro: o rebaixamento da formação humanista em todos os níveis de ensino, levando moradores e turistas a terem comportamentos sociais inadequados frente ao patrimônio, em espetáculos musicais ou de artes cênicas.

3. Relativamente ao tema turismo e cultura, que balanço faz do estado da arte no seu país, na área das Ciências Sociais ou Humanas?

Por muito tempo, o marketing turístico brasileiro centrou-se na erotização do país e das pessoas. Em anos recentes, o marketing passou a priorizar a exuberância da 
natureza tropical e a diversidade cultural. Estas ações públicas têm sido muito estudadas nas Ciências Sociais, de modo crítico. Como fenômeno recente, houve a ascensão de Estudos Turísticos em cursos de mestrado e doutorado exclusivos, a partir dos anos 2000. Muitos deles associam os Estudos Socioculturais em suas linhas de pesquisa, mas infelizmente ainda com grande ênfase em estudos de caso descritivos e pouco analíticos. Há muitos estudos sobre festas e, também, a gastronomia é temática emergente de pesquisa, assim como o patrimônio arquitetônico e a questão urbana, associando turismo e cultura. Indicativos importantes sobre a presença de novos enfoques acadêmicos é a premiação da Associação Nacional de Pesquisa em Turismo (ANPTUR) para dissertações que alcancem excelência, onde já foram premiadas investigações das Ciências Sociais. Destaco especialmente trabalhos de uma colega na Universidade, que nos últimos dois anos teve pesquisas por ela orientados entre os três finalistas na ANPTUR, ambos metodologicamente associados à Análise do Discurso de linha francesa, protagonizada por Michel Pêcheux. Os resultados são muito estimulantes.

4. É sabido que a atividade turística é muito suscetível às intempéries políticas, econômicas, sociais e ecológicas. Como o turismo localmente vem se modificando por conta destes e/ou de outros aspectos conjunturais?

Em anos recentes, políticas públicas que favoreceram criação de empregos e melhor distribuição de renda, levaram ao crescimento do turismo interno no Brasil. O câmbio favorável favoreceu as viagens ao exterior, em muito motivadas por turismo de compras. A crise 2016-2018 afastou camadas populares que haviam sido incorporadas ao consumo turístico, ao mesmo tempo em que redirecionou as camadas médias das viagens ao exterior para o turismo doméstico. Em termos acadêmicos, tanto na pesquisa como no ensino, a área ainda é muito sensível a presença de políticas públicas de incentivo.

5. Do ponto de vista da sua área de atuação que arranjos ou conexões teóricas, metodológicas e deontológicas vêm se desenhando ultimamente? Quais as perspetivas futuras?

Como colocado anteriormente, presenciamos nos últimos 20 anos, a constante presença de pesquisas em Turismo em cursos de mestrado e doutorado, assim como uma visão menos operacional dos cursos de graduação. Dissertações e teses elaboradas por pesquisadores com toda sua formação superior - da graduação à pós-graduação em Turismo representam uma intervenção acadêmica com outro tipo de olhar. Teremos pesquisadores com aportes teóricos e metodológicos filtrados por vivencias internas ao turismo, que deverão apresentar boas surpresas nos estudos acadêmicos.

Nas universidades brasileiras ainda é forte a presença de pesquisadores com formação na História, Sociologia e Antropologia. A História, quando utiliza uma visão crítica e complexa, tem superado o descritivo cronológico e apresentado resultados muito interessantes. A história do turismo no Brasil tem ganho importantes contribuições, libertando-se dos fatos e das datações exclusivamente europeias. 
E, como já colocado, tem sido muito rica a contribuição das metodologias semióticas, como a análise do discurso e a análise de conteúdo. A maior produção de pesquisas levou ao surgimento de inúmeros periódicos e eventos científicos, dando visibilidade e densidade aos estudos acadêmicos.

Caxias do Sul, Brasil, outubro, 2018 